\title{
UPAYA PENGENALAN PAKAIAN ADAT INDONESIA PADA ANAK SEKOLAH DASAR, MENGGUNAKAN AUGMENTED REALITY PADA BOOK DESIGN
}

\author{
Clara Riyanti Teresa, Berti Alia Bahaduri, Sandy Rismantojo \\ (Email:dac_obi@yahoo.co.id) \\ Desain Komunikasi Visual \\ Fakultas Seni Rupa dan Desain \\ Universitas Kristen Maranatha \\ Jl. Prof.drg. Suria Sumantri, MPH no. 65, Bandung, Indonesia
}

\begin{abstract}
ABSTRAK
Indonesia merupakan negara kepulauan dengan berbagai kebudayaan, salah satu hasil budayanya adalah pakaian adat. Menurut kurikulum Sekolah Dasar Indonesia tahun 2013, materi pakaian adat Indonesia diajarkan pada kelas 4 sekolah dasar. Penulis mendapat fakta bahwa hanya sedikit anakanak yang tertarik dengan pakaian adat Indonesia karena media pembelajaran yang digunakan sangat minim dan tidak menarik. Kemajuan teknologi saat ini khususnya pada smartphone dapat menjadi sarana terbaik untuk menerapkan edukasi yang lebih menarik bagi anak-anak. Perancangan ini bertujuan untuk mengenalkan pakaian adat Indonesia dengan cara yang menarik dan inovatif sehingga membangkitkan minat belajar anak-anak. Menggunakan media buku interaktif sebagai media utama dan memanfaatkan ketertarikan anak-anak terhadap smartphone untuk memberikan materi pengajaran tentang Pakaian adat Indonesia. Metode yang digunakan untuk pengumpulan data adalah studi pustaka dan wawancara. Selanjutnya, didapatkan data mengenai preferensi belajar anak-anak dan gaya ilustrasi yang disukai oleh target. Sehingga tahap berikutnya adalah penggambaran pakaian-pakaian daerah menggunakan gaya ilustasi yang menarik. Sisi interaktif peek-a-boo diterapkan menggunakan aplikasi smartphone sebagai pendukung dengan fitur audio yang menarik. Melalui perancangan ini, diharapkan anak-anak dapat mengenal dan tertarik dengan Pakaian adat Indonesia sehingga Pakaian adat Indonesia dapat dikenal sejak dini.
\end{abstract}

Kata kunci : anak-anak, buku; interaktif; pakaian adat Indonesia

\begin{abstract}
Indonesia is an archipelago with a variety of cultures, one of which is the traditional clothing. According to the Indonesian elementary school curriculum in 2013, the contents about Indonesian Traditional Clothing are taught in grade four elementary school. The writer gathered the fact that only a few children who are interested in Indonesian Traditional Clothing because the learning media is very minimal and unattractive. The improvements of technology especially on smartphone can be the best way to apply the more attractive education for children. This design aims to introduce Indonesian Traditional Clothing in interesting and innovative ways to improve children's interest. It also uses attractive media in books and takes advantage of the children's smartphone to teach the material of Indonesian Traditional Clothing. Through this design, the book still serves as the main medium of learning; to attract children to learn about Indonesia clothing can be delivered effectively. The method used to collect data are literatures study and interview, then experiments in drawing the traditional costumes using the preferable illustration style. The final stag is to create an interactive book that integrates with smartphone applications to convey information about Indonesian Traditional Clothing children. The book is completed with interesting visual and peek-a-boo interactive that can be connected to a smartphone application as a supporting medium with audio features. Through this book design, children can get to know and be interested in Indonesian Traditional Clothing, so it can be known from the early age.
\end{abstract}

Keywords: book; children; Indonesian traditional clothing; interactive 


\section{PENDAHULUAN}

Indonesia merupakan negara kepulauan yang memiliki kebudayaan yang beragam. Salah satu unsur kebudayaan yang dimiliki Indonesia adalah pakaian adat yang merupakan representasi kebudayaan paling tinggi di sebuah komunitas masyarakat di daerah tertentu, sehingga perlu adanya sebuah upaya untuk menjaga dan melestarikan keberadaan pakaian adat. Upaya ini bertujuan agar masyarakat saat ini bisa mengetahui, memahami dan mengambil nilai-nilai positif yang terkandung pada pakaian adat di daerah mana saja.

Pakaian adat dijumpai kembali dalam pelajaran Ilmu Pengetahuan Sosial di bangku kelas 4 sekolah dasar. Melalui wawancara yang dilakukan kepada anak-anak sekolah dasar, sebagian besar dari mereka tidak tertarik dengan pakaian adat, bahkan ada yang tidak ingat dengan adanya pelajaran pakaian adat Indonesia. Responden awal ini juga belum mengetahui mengenai keberagaman pakaian adat dari pulau-pulau di Indonesia.

Sumber data berupa buku yang tersedia juga belum cukup menarik bagi anak-anak usia 10 - 12 tahun (setara kelas 4-6 Sekolah Dasar). Melihat fenomena perkembangan teknologi saat ini, berpengaruh pada kesenangan anak-anak saat ini yang lebih tertarik dengan smartphone yang memiliki banyak hiburan dalam bentuk yang praktis. Oleh karena itu Pakaian Adat Nusantara akan dikenalkan melalui perancangan buku interaktif yang melibatkan smartphone sebagai alat bantu dan buku sebagai sumber data yang tahan lama.

\section{METODE PERANCANGAN \\ Buku interaktif}

Interaktif adalah bersifat saling melakukan aksi, antar hubungan, saling aktif, sedangkan buku adalah kumpulan kertas yang dijilid. Dengan demikian, buku interaktif dapat berarti sebagai lembar kertas yang berjilid yang dapat melakukan aksi, hubungan, dan saling aktif antara buku dan pembacanya.

\section{Buku Interaktif "Peek-a-boo"}

Merupakan buku interaktif dengan halaman-halaman yang memiliki kejutan atau informasi lain di balik lipatan pada halaman tersebut (Annehaira,2016).

\section{Augmented Reality (AR)}

Teknologi yang menggabungkan benda maya dua dimensi dan atau benda tiga dimensi ke dalam sebuah lingkungan nyata tiga dimensi yang kemudian diproyeksikan menjadi bentuk yang terlihat nyata di dalam layar. AR tidak sepenuhnya menggantikan kenyataan, tetapi hanya menambahkan atau melengkapi kenyataan. 
Benda-benda maya menampilkan informasi yang tidak dapat diterima oleh pengguna dengan inderanya sendiri. Hal ini membuat AR menjadi alat untuk membantu memberi informasi dan membuat penggunanya berinteraksi dengan dunia nyata. Informasi yang ditampilkan oleh benda maya membantu pengguna melaksanakan kegiatan-kegiatan dalam dunia nyata. Augmented Reality dapat diaplikasikan untuk indera manusia termasuk penglihatan, pendengaran, sentuhan. Selain digunakan dalam bidang seperti kesehatan, militer, industri manufaktur, AR telah diaplikasikan dalam perangkat-perangkat yang digunakan orang banyak seperti pada smartphone (Dwika,2012).

\section{Tata Letak}

Tata letak atau yang biasa disebut dengan layout adalah pengaturan tulisan-tulisan dan gambar-gambar yang digunakan untuk menyampaikan pesan kepada penggunanya. Layout yang baik memiliki tiga kriteria, yaitu : It Works (mencapai tujuan), It Organizes (ditata dengan baik) dan It Attracts (menarik bagi pengguna). Sebuah layout dapat bekerja dan mencapai tujuannya bila pesan-pesan yang akan disampaikan dapat segera ditangkap dan dipahami oleh pengguna dengan suatu cara tertentu. Selanjutnya, sebuah layout harus ditata dan dipetakan secara baik supaya pengguna dapat berpindah dari satu bagian ke bagian yang lain dengan mudah dan cepat. Akhirnya, sebuah layout harus menarik untuk mendapatkan perhatian yang cukup dari penggunanya (Sutanto, 2002).

\section{PEMBAHASAN}

Pada perancangan buku interaktif ini, penulis memilih target anak-anak kelas 4-6 sekolah dasar di kota-kota besar di Indonesia, usia 9-12 tahun kelas menengah ke atas yang bergaya hidup modern dengan orangtua yang mementingkan pendidikan dan peduli dengan budaya Indonesia. Buku interaktif berisi materi pakaian adat khas Indonesia yang memperkenalkan macam-macam pakaian adat dan cara penggunaannya serta sejarah dari pakaian tersebut, dengan tampilan menarik dan dapat bergabung dengan aplikasi pada smartphone.

Dalam perancangan ini, buku interaktif pakaian adat dapat berintegrrasi dengan smartphone menggunakan teknologi Augmented Reality yang dapat membuat gambar menjadi nyata di dalam layar smartphone, sehingga dapat menarik minat anak dalam mempelajari pakaian adat. 
Gaya visual yang digunakan sesuai dengan preferensi reponden dalam wawancara, yaitu menggunakan garis pinggir/ outline, perbandingan kepala dengan badan 1: 3 dan bentuk kepala yang lonjong.

Buku interaktif ini dikemas dalam bentuk serial dengan judul "Yuk Kenali Pakaian Tradisional!", Berikut adalah cover serial :
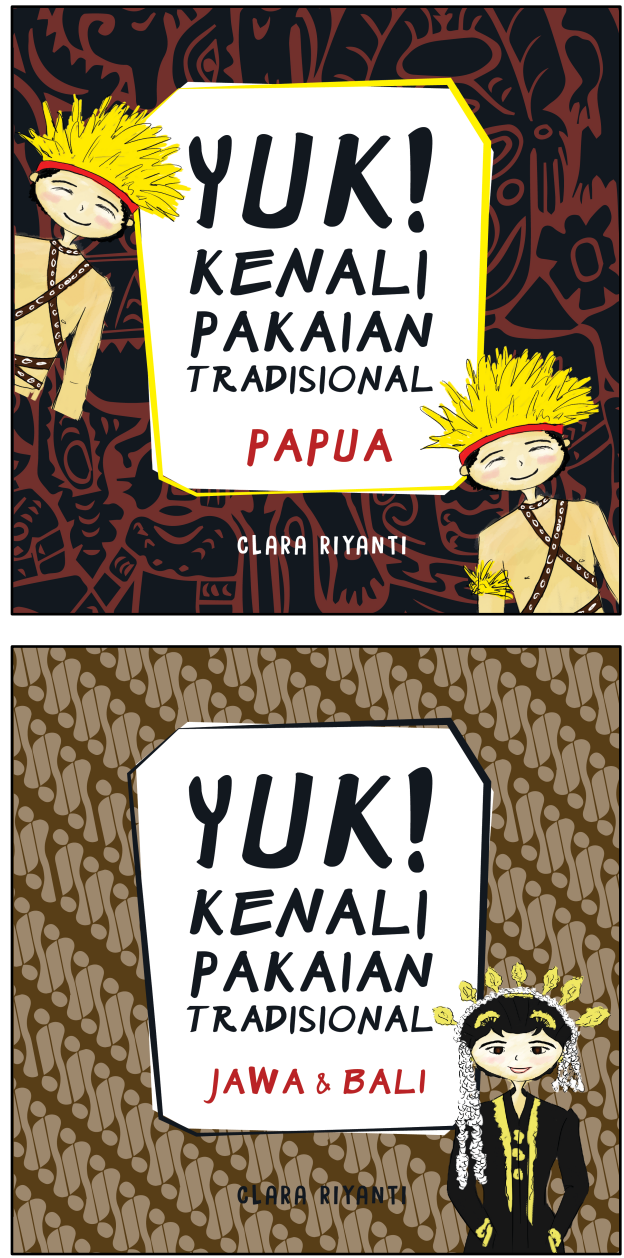

Gambar 1. Cover Luar Serial Sumber: Hasil Karya Penulis, 2016

Pada perancangan ini, sebagai proyek percontohan seri pertama yang akan dibuat adalah membuat buku "Pakaian Tradisional Sumatera", sebagai pulau paling Timur di Indonesia. 


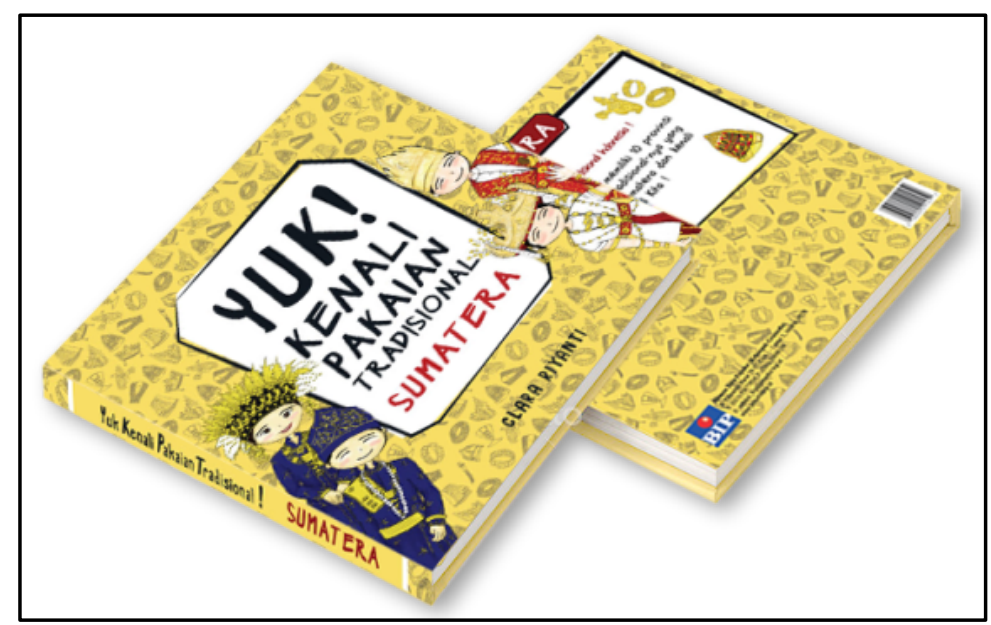

Gambar 2. Cover Luar Seri Sumatera

Sumber: Hasil Karya Penulis, 2016

Sebagian besar pakaian tradisional Sumatera memiliki warna-warna panas seperti kuning, merah dan hitam,sehingga penulis menyeimbangkan warna-warna tersebut dengan warna putih dan tugois muda untuk membuat warna kontras yang disukai target. Menggunakan tipografi yang disesuaikan dengan target, tipografi yang mudah dibaca dengan karakter yang playfull untuk anak-anak. Dalam perancangan ini terdapat 2 (dua) media utama yaitu buku interaktif dan aplikasi pada smartphone.

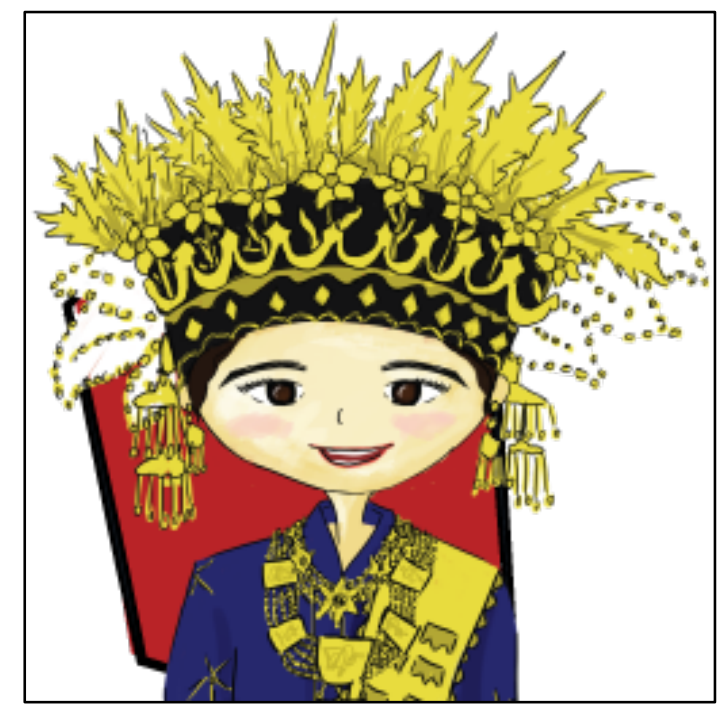

Gambar 3. Detail Aplikasi ikon Sumber: Hasil Karya Penulis, 2016 


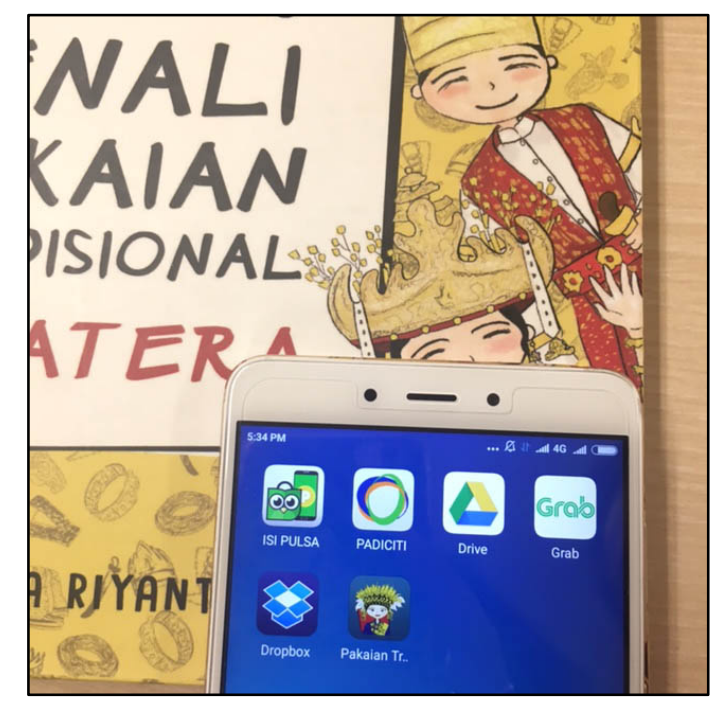

Gambar 4. Aplikasi ikon

Sumber: Hasil Karya Penulis, 2016

Aplikasi AR akan diaplikasikan untuk melihat detail pakaian adat, penjelasan dalam bentuk tulisan, serta lagu daerah. Pembaca dapat melihat pakaian adat dari beberapa sisi dan mendapat informasi yang tidak terdapat di dalam buku. Sehingga interaksi sekaligus berfungsi sebagai pelengkap informasi dari setiap pakaian adat.

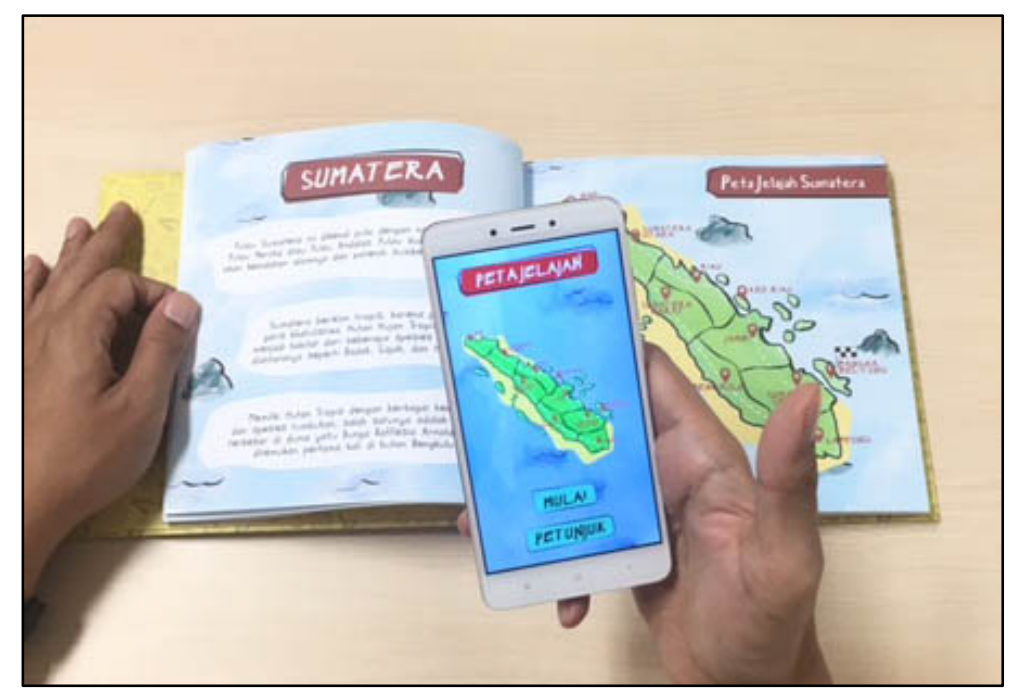

Gambar 5. Halaman awal aplikasi Sumber: Hasil Karya Penulis, 2016 
Serat Rupa Journal of Design, May 2017, Vol.1, No.3: 508-521

Clara Riyanti Teresa, - Upaya Pengenalan Pakaian Adat Indonesia Pada Anak Sekolah Dasar, Menggunakan Augmented Reality Pada Book Design.

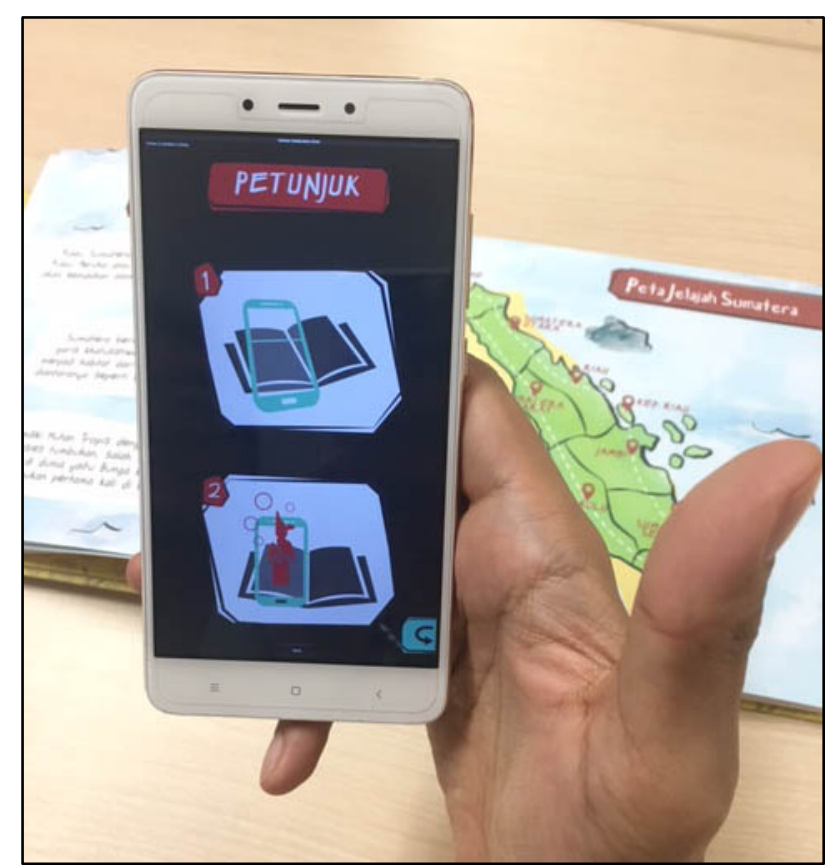

Gambar 6. Petunjuk penggunaan aplikasi Sumber: Hasil Karya Penulis, 2016

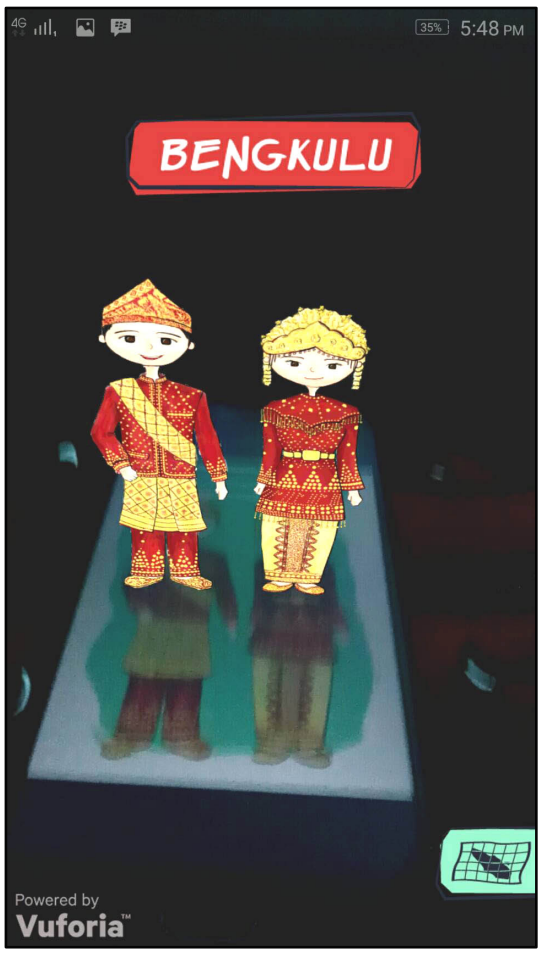

Gambar 7. Contoh Pemindaian ilustrasi buku menggunakan aplikasi Sumber: Hasil Karya Penulis, 2016

Penulis juga membuat beberapa media tambahan yang dijadikan hadiah pada pembelian buku, yaitu poster pakaian adat dan pembatas buku yang dapat berguna untuk pembelajaran anak. 


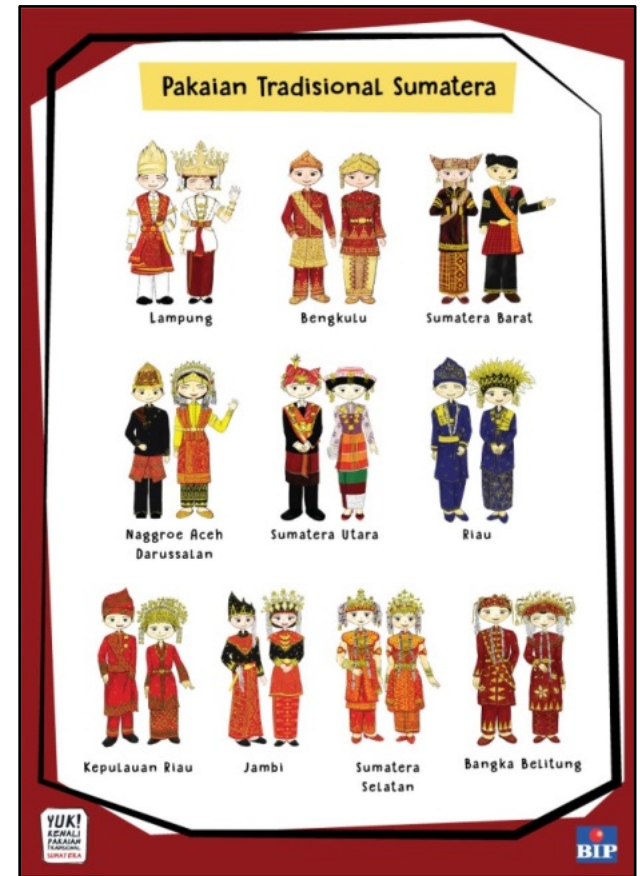

Gambar 8. Poster Pakaian adat Sumber: Hasil Karya Penulis, 2016

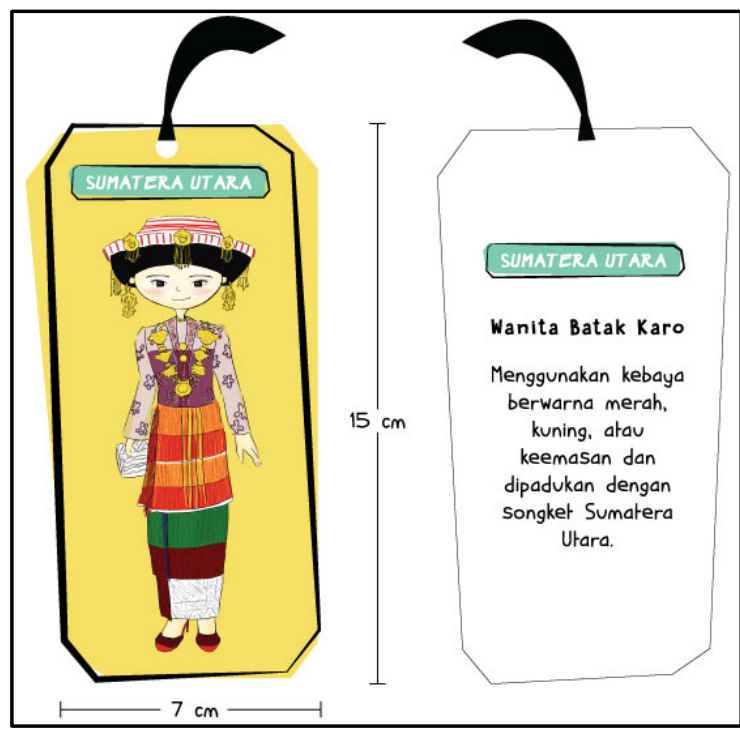

Gambar 9. Pembatas Buku

Sumber: Hasil Karya Penulis, 2016

Media promosi yang digunakan pada saat peluncuran buku adalah poster, $x$-banner dan iklan pada media sosial.

Halaman dalam dari buku ini menggunakan tata letak 1 spread untuk setiap propinsi. Peletakan ini memudahkan pembaca untuk memindai gambar menggunakan aplikasi dan 
membuka jendela-jendela yang menutupi sebagian gambar. Dimulai dengan pengenalan daerah melalui peta Indonesia.

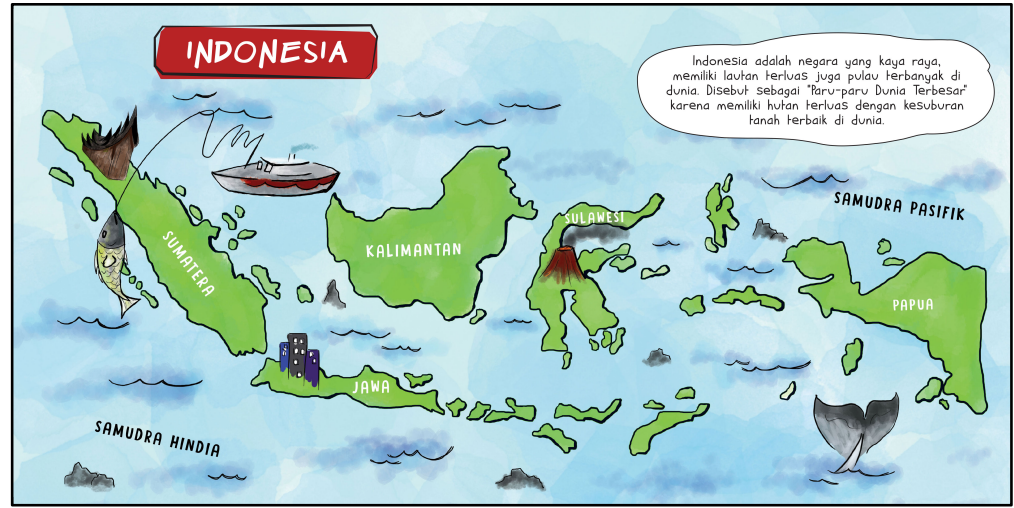

Gambar 10. Pengenalan Peta Indonesia Sumber: Hasil Karya Penulis, 2016

Kemudian dilanjutkan dengan pengenalan Pulau Sumatera, agar pembaca dapat mengetahui batas-batas propinsi di Sumatera.

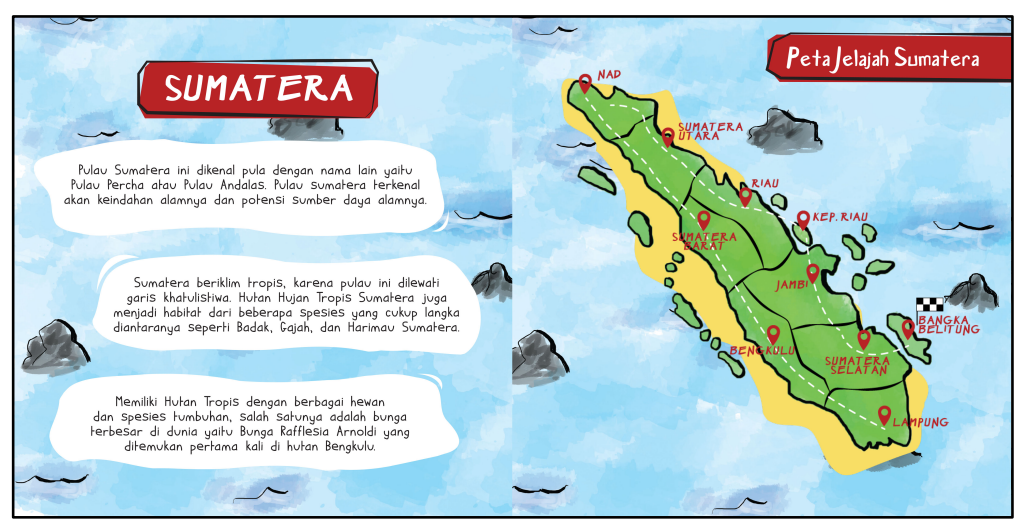

Gambar 11. Pengenalan Pulau Sumatera Sumber: Hasil Karya Penulis, 2016

Berikut adalah contoh tata letak halaman setiap propinsi.

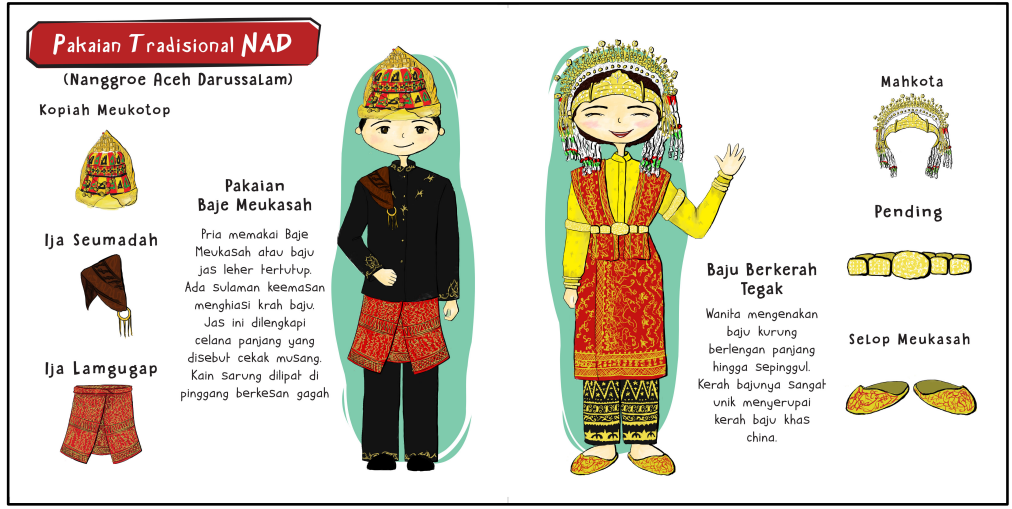

Gambar 12. Tata letak halaman Nanggroe Aceh Darussalam Sumber: Hasil Karya Penulis, 2016 
Serat Rupa Journal of Design, May 2017, Vol.1, No.3: 508-521

Clara Riyanti Teresa, - Upaya Pengenalan Pakaian Adat Indonesia Pada Anak Sekolah Dasar, Menggunakan Augmented Reality Pada Book Design.

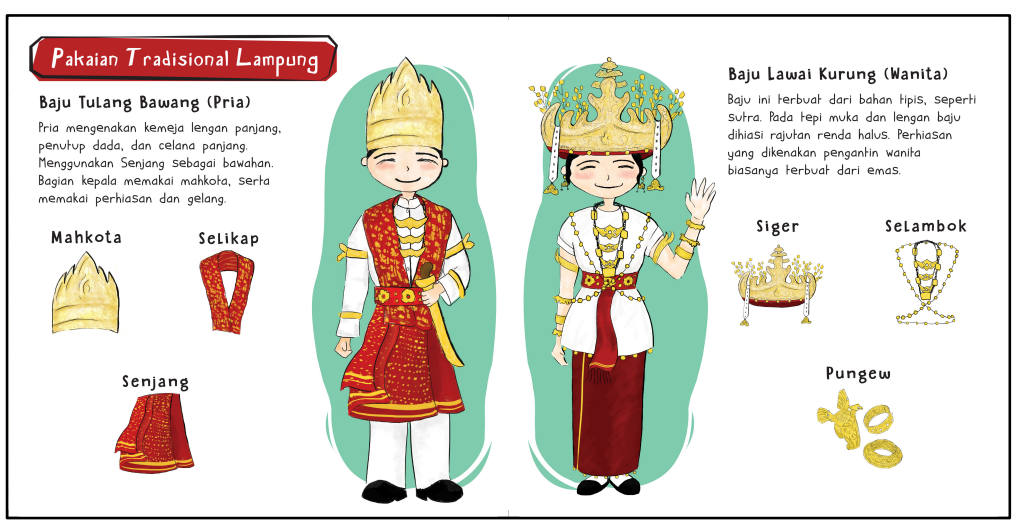

Gambar 13 Tata letak halaman Sumatra Utara

Sumber: Hasil Karya Penulis, 2016

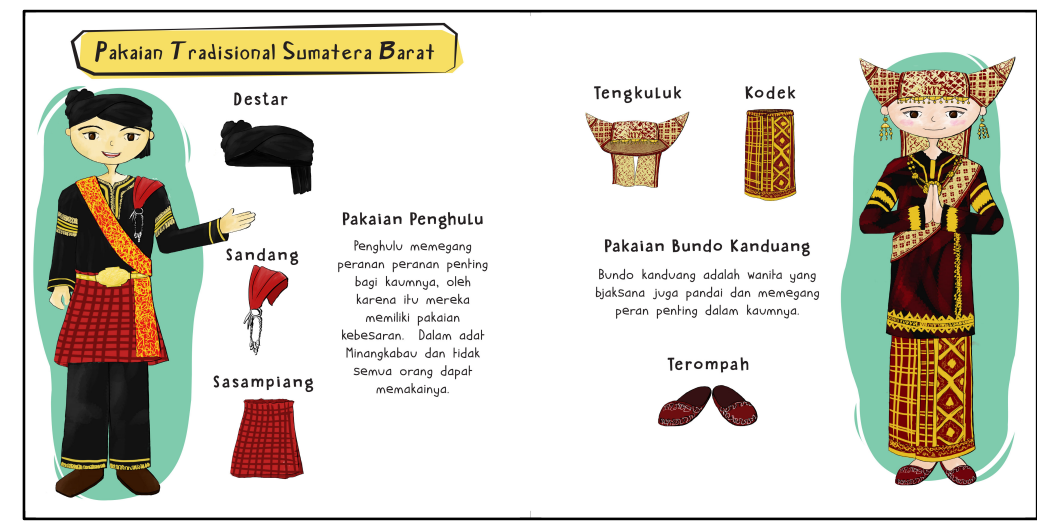

Gambar 14. Tata letak halaman Sumatra Barat Sumber: Hasil Karya Penulis, 2016

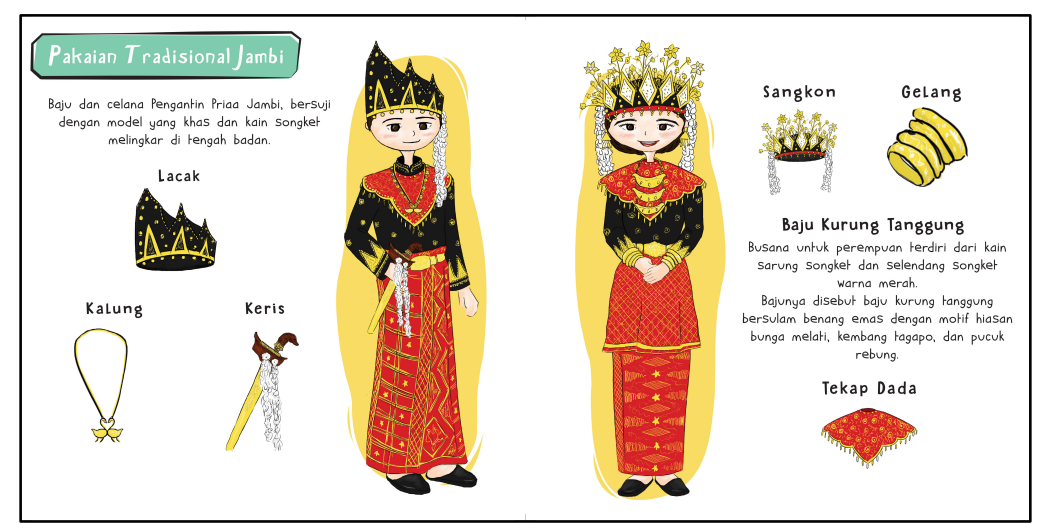

Gambar 15. Tata letak halaman Jambi Sumber: Hasil Karya Penulis, 2016 
Serat Rupa Journal of Design, May 2017, Vol.1, No.3: 508-521

Clara Riyanti Teresa, - Upaya Pengenalan Pakaian Adat Indonesia Pada Anak Sekolah Dasar, Menggunakan Augmented Reality Pada Book Design.

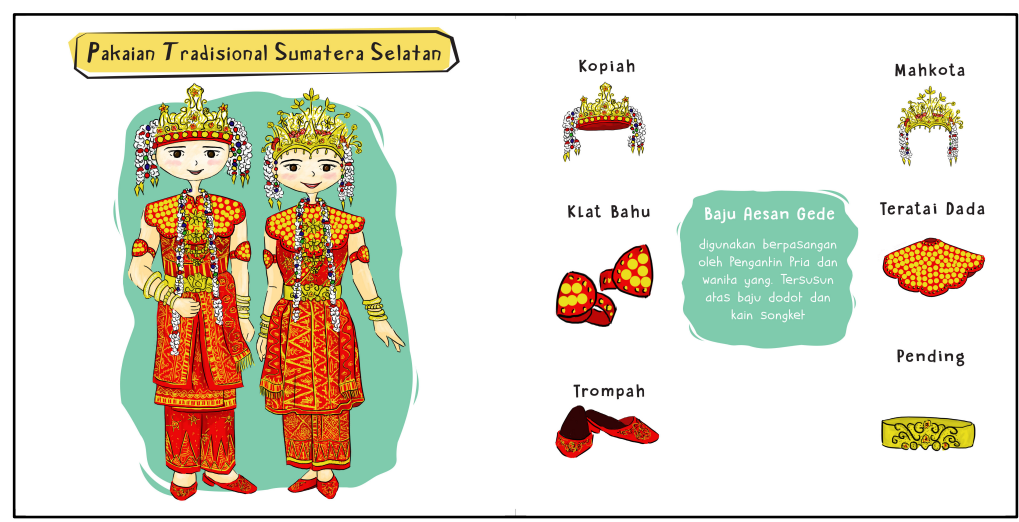

Gambar 16. Tata letak halaman Sumatra Selatan Sumber: Hasil Karya Penulis, 2016

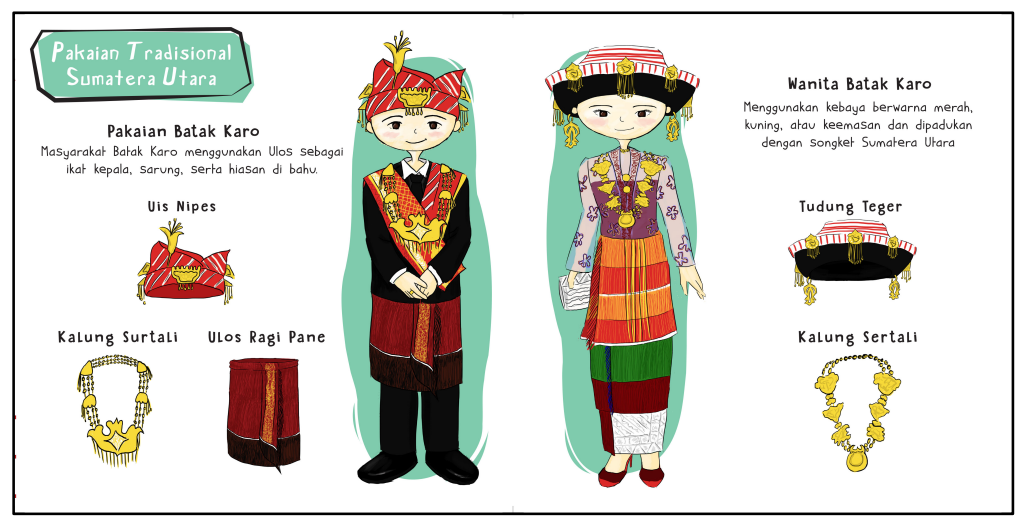

Gambar 17. Tata letak halaman Lampung Sumber: Hasil Karya Penulis, 2016

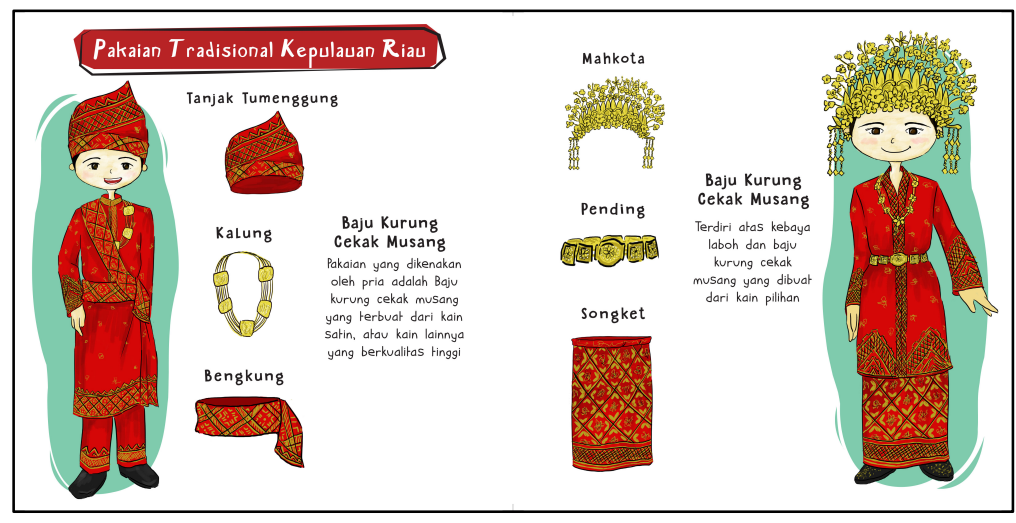

Gambar 18. Tata letak halaman Kepulauan Riau Sumber: Hasil Karya Penulis, 2016 


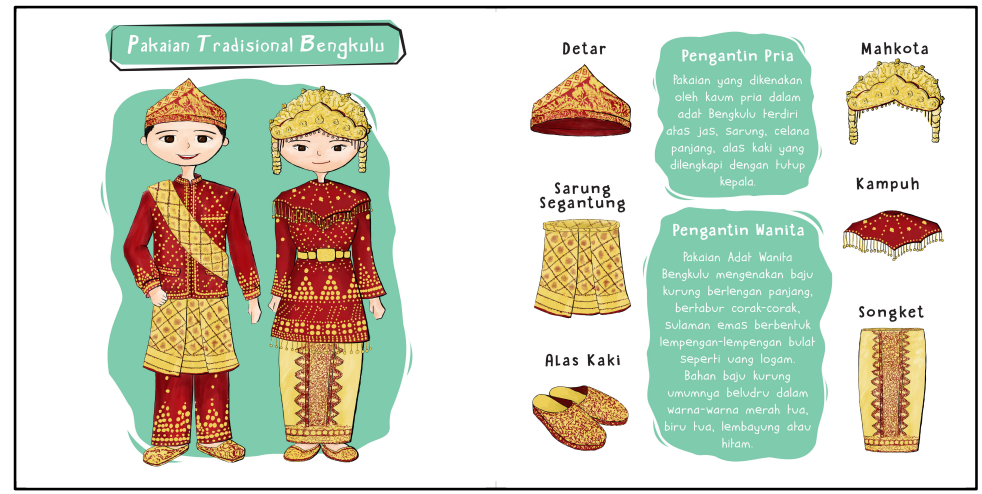

Gambar 19. Tata letak halaman Bengkulu Sumber: Hasil Karya Penulis, 2016

\section{PENUTUP}

Pakaian Tradisional Indonesia yang merupakan salah satu hasil budaya Indonesia, diperkenalkan pertama kali di bangku kelas 4 sekolah dasar. Materi pakaian tradisional disampaikan melalui buku pelajaran, namun sangat disayangkan bahwa hanya terdapat 1 (satu) lembar yang berisikan materi Pakaian Tradisional Indonesia. Hal ini dirasa kurang memberi informasi kepada anak-anak. Banyak orangtua saat ini sudah memberikan smartphone kepada anak, hal ini membuat anak-anak saat ini tidak dapat lepas dari smartphone. Walaupun berdampak negatif pada buku dan permainan-permainan tradisional menjadi ditinggalkan, perkembangan teknologi ini dapat dimanfaatkan untuk memasukkan materi-materi pembelajaran budaya tradisional dengan cara yang modern. Pembelajaran melalui buku interaktif yang berintegrasi dengan aplikasi smartphone dapat menjadi cara yang efektif sebagai media pembelajaran budaya tradisional.

Melalui buku interaktif yang telah dibuat, disampaikan materi pembelajaran pakaian tradisional Sumatera yang digunakan oleh pengantin pria dan wanita beserta aksesorisaksesoris yang digunakan. Buku dibuat dengan interaktif peek-a-boo yang memberikan penjelasan di balik gambar. Terdapat aplikasi pada smartphone yang dapat memberikan efek hidup pada tokoh, juga terdapat lagu daerah sebagai backsound.

Perancangan buku interaktif ini bertujuan untuk mengenalkan pakaian tradisional Indonesia yang menarik, inovatif dan menjadi minat belajar bagi anak-anak. Pengenalan budaya kepada anak sejak dini akan mengajarkan anak untuk mengenal negaranya dan membangun rasa nasionalisme, melestarikan nilai-nilai luhur budaya dan menghargai keberagaman budaya bangsa, khususnya pakaian tradisional. 


\section{DAFTAR PUSTAKA}

Kristiani, Dian. 2016. Ensiklopedia Negeriku: Pakaian adat. Jakarta: Bhuana Ilmu Populer.

Santoso, Tien. 2010. Tata Rias dan Busana Pengantin Seluruh Indonesia. Jakarta : PT. Gramedia Pustaka Utama.

Sarwono, Sarlito W. 2013, Psikologi Remaja. Jakarta: Penerbit Mandar Maju.

\section{Sumber online:}

Admin. 1 Maret 2015, "Pengertian dan Tujuan Pendidikan di Sekolah Dasar", (Online), (http://disdik.bekasikab.go.id/berita-pengertian-dan-tujuan-pendidikan-di-sekolahdasar.html, diakses 25 Februari 2016 pukul 13:11 WIB)

Anneahira.com Content Team. "Buku Fiksi", (Online), (http://www.anneahira.com/bukufiksi.htm). Diakses pada 29 Februari 2016, pukul 17:12 WIB

Dwi Kristianto, ST. 2002. "Layout yang baik”, (Online),

(http://faculty.petra.ac.id/dwikris/docs/desgrafisweb/layout_design/layout_baik.html , diakses 4 April 2016, pukul 18:04 WIB)

Habibullah AI Faruq. 19 Agustus 2015. "Jenis-Jenis Gambar Ilustrasi", (Online), (http://www.habibullahurl.com/2015/08/jenis-jenis-gambar-ilustrasi.html, diakses 4 April 2016, pukul 17: 21 WIB)

Oey, Fanny; Waluyanto, Heru; Zacky, Asnar . “Perancangan Buku Interaktif Pengenalan dan Pelestarian Sugar Glider di Indonesia Bagi Anak 7-12 Tahun". Surabaya : Fakultas Seni dan Desain, Universitas Kristen Petra. Diakses pada 27 Februari 2016 pukul 11:10 WIB

Rahma, Dwika. 2012. “Rancang Bangun Aplikasi Kamus Irregular Verb Berbasis Mobile pada Platform Android". Fakultas MIPA, Universitas Lampung.

Ubay. 17 Oktober 2015. "Pengertian Buku Non Fiksi Beserta Jenisnya Lengkap", (Online), (http://www.seputarpendidikan.com/2015/10/pengertian-buku-non-fiksi-besertajenis-jenisnya-lengkap.html). Diakses pada 29 Februari 2016, pukul 17:20 WIB

"Apakah Augmented Reality itu?", (Online), (augmentedrealityindonesia.com, diakses 27 Februari 2016 pukul 16:44 WIB)

"Pengertian dan Fungsi Pakaian Serta Perbedaan Busana dan Pakaian", (Online), (http://artikel.janaku.com/2014/02/pengertian-dan-fungsi-pakaian-serta.html diakses 24 Februari 2016 pukul 14:21 WIB)

"Pengertian dan Tujuan Smartphone", (Online), (https://smartphoneterbaru.wordpress.com/2013/03/14/pengertian-dan-tujuansmartphone diakses 26 Februari 2016 pukul 15:32 WIB) 
Serat Rupa Journal of Design, May 2017, Vol.1, No.3: 508-521

Clara Riyanti Teresa, - Upaya Pengenalan Pakaian Adat Indonesia Pada Anak Sekolah Dasar, Menggunakan Augmented Reality Pada Book Design.

"Pengertian Pakaian adat - Pakaian adat dari Berbagai Daerah", (Online),

(http://www.anneahira.com/pengertian-pakaian-adat.htm, diakses 24 Februari 2016 pukul 14:25 WIB)

"RPP Kurikulum KTSP Kelas 1, 2, 3, 4, 5 dan 6 SD", (Online),

(www.sekolahdasar.net, diakses 25 Februari 2016 pukul 11: 35 WIB) 